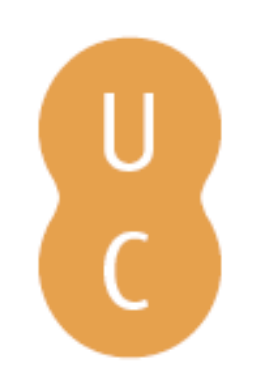

\title{
nombalina
}

\section{António Simões, um académico pioneiro da educação permanente e de adultos em Portugal}

\author{
Autor(es): Lima, Licínio \\ Publicado por: Imprensa da Universidade de Coimbra \\ URL \\ persistente: URI:http://hdl.handle.net/10316.2/31227 \\ DOI: $\quad$ DOI:http://dx.doi.org/10.14195/978-989-26-0228-8_2 \\ Accessed : $\quad$ 26-Apr-2023 07:18:49
}

A navegação consulta e descarregamento dos títulos inseridos nas Bibliotecas Digitais UC Digitalis, UC Pombalina e UC Impactum, pressupõem a aceitação plena e sem reservas dos Termos e Condições de Uso destas Bibliotecas Digitais, disponíveis em https://digitalis.uc.pt/pt-pt/termos.

Conforme exposto nos referidos Termos e Condições de Uso, o descarregamento de títulos de acesso restrito requer uma licença válida de autorização devendo o utilizador aceder ao(s) documento(s) a partir de um endereço de IP da instituição detentora da supramencionada licença.

Ao utilizador é apenas permitido o descarregamento para uso pessoal, pelo que o emprego do(s) título(s) descarregado(s) para outro fim, designadamente comercial, carece de autorização do respetivo autor ou editor da obra.

Na medida em que todas as obras da UC Digitalis se encontram protegidas pelo Código do Direito de Autor e Direitos Conexos e demais legislação aplicável, toda a cópia, parcial ou total, deste documento, nos casos em que é legalmente admitida, deverá conter ou fazer-se acompanhar por este aviso.

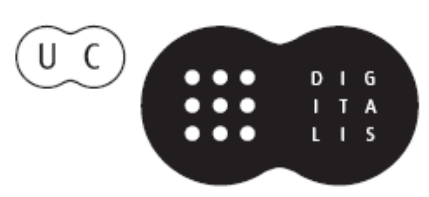




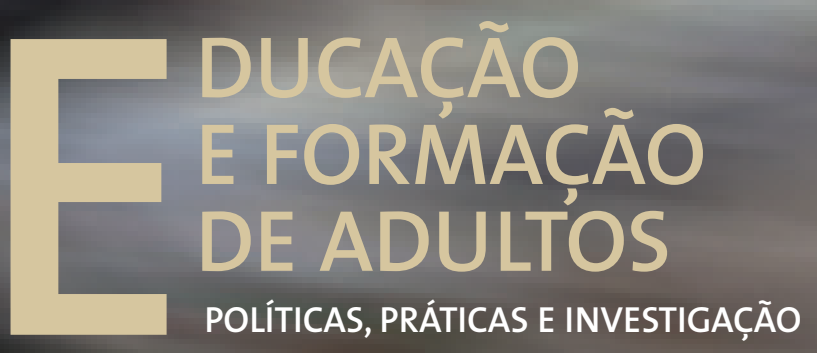

Luís Alcoforado • Joaquim Armando G. Ferreira António Gomes Ferreira • Margarida Pedroso de Lima Cristina Vieira • Albertina L. Oliveira • Sónia Mairos Ferreira 


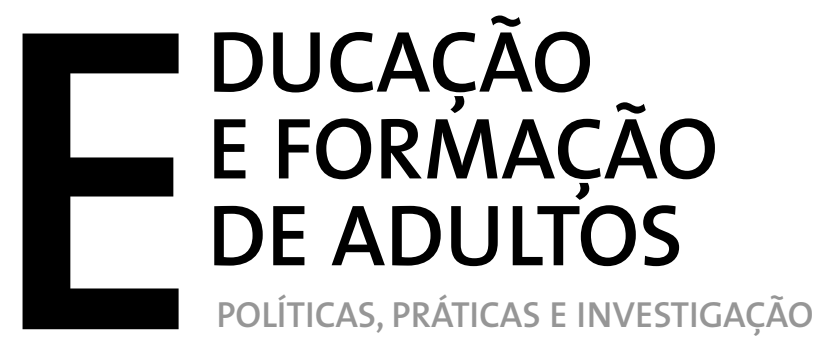

Luís Alcoforado • Joaquim Armando G. Ferreira António Gomes Ferreira - Margarida Pedroso de Lima Cristina Vieira • Albertina L. Oliveira • Sónia Mairos Ferreira 
EDIÇÃo

Imprensa da Universidade de Coimbra

URL: http://www.uc.pt/imprensa_uc

Vendas online: http://www.livrariadaimprensa.com

CONCEPÇÃO GRÁFICA

António Barros

Pré-Impressáo

SerSilito-Empresa Gráfica, Lda

EXECUÇÃo GRÁFICA

SerSilito-Empresa Gráfica, Lda

ISBN

978-989-26-0136-6

DePósito LEgaL

$340309 / 12$ 



\section{António Simóes, um académico pioneiro da Educaçáo Permanente e de Adultos em Portugal}

Licínio Lima

Universidade do Minho

Está por realizar, entre nós, um "estado da arte" da produção académica portuguesa em Educação de Adultos. A tarefa é tão necessária quanto arriscada, e este não é o único paradoxo que em seu torno se pode identificar. Por um lado lamentamo-nos, com frequência, da falta de tradição educativa, política e também académica da Educação de Adultos em Portugal, facto incontornável quando comparado com a generalidade dos países da Europa, com os Estados Unidos da América e, até mesmo, com o Brasil, por exemplo. Isso acarretou uma emergência tardia, e em pequeno número, da produção científica e pedagógica no domínio, sempre muito difícil à margem de instituiçôes de ensino superior especializadas em educação e de práticas socioeducativas que estimulassem reflexóes sistemáticas e ideários educativos congruentes. Mas, por outro lado, a nossa falta de tradição e a correspondente escassez de trabalhos parece induzir, contraditoriamente, pouco estudo acerca dos contributos disponíveis, de que resulta um certo desconhecimento de um campo académico que seria, teoricamente, relativamente fácil de inventariar e de conhecer. Acresce a tudo isto a conhecida tendência portuguesa para apreciar os autores estrangeiros, de que resulta um certo cosmopolitismo e alguma erudição, embora, por vezes, lamentavelmente sustentados pela ignorância daqueles que nos precederam e de alguns dos mais importantes contributos nacionais. Em resumo, queixamo-nos, compreensivelmente, de uma herança marcada por poucos contributos académicos na nossa área de investigação, mas, não obstante, nem os contributos que consideramos escassos acabamos por conhecer em profundidade para, com eles, estabelecer diálogo, crítica ou ruptura.

Nada disto, porém, diminui os impactos fortíssimos, no nosso campo, da história portuguesa, pouco letrada, ao longo do século XX. Náo obstante os discursos políticoeducativos, a legislaçáo e certas realizaçóes do regime republicano, algumas das quais estudadas por Rogério Fernandes, especialmente através das questóes da alfabetização e da educação popular, o que dominou durante a maior parte do século XX foi uma política educativa que Alberto Melo apelidou de "obscurantismo programado". O desenvolvimento da Educação de Adultos, fosse pela via dos movimentos sociais, do sindicalismo, dos partidos políticos ou da Igreja, fosse pela via da emergência do Estado-providência e de políticas públicas de signo social-democrata, em parte simbolizadas pelas conferências e declaraçóes da UNESCO e por textos fundadores como os de Robert Hutchins, Paul Lengrand ou Edgar Faure, sob os lemas da "sociedade da aprendizagem" e da "educação permanente" ou "educação ao longo da vida", revelava-se uma impossibilidade em Portugal, durante o regime autoritário. Ambas as vias mencionadas exigiam um regime democrático, ou o processo de luta pela sua construção, a participação cívica e cidadã e não a aquiescência e a passividade, a esperança e náo o fatalismo, o reconhecimento da cultura popular e dos saberes dos sujeitos, mesmo os dos analfabetos, náo a sua desvalorização e muito menos o receio da sua contaminação pela letras e respectiva perda do carácter rústico e dócil que era atribuído à classe popular iletrada. Neste particular, creio que em termos de orientaçóes 
dominantes de política educativa, cedo passamos de uma situação em que a educação não servia para nada, para um contexto de elogio hiperbólico das propriedades salvíficas da formação, das competências e das habilidades para a empregabilidade, a competitividade e a adaptação ao trabalho no novo capitalismo. Como se a aprendizagem ao longo da vida, especialmente entendida como processo de individualização e de performance competitiva, tudo pudesse fazer ou realizar, agora no quadro de um novo pedagogismo de extracção económica e gerencial e num contexto em que a educação se encontra em processo de colonização pela economia.

Até como contraponto às derivas técnico-instrumentais e funcionalistas do paradigma mais recente da "aprendizagem ao longo da vida", tal como este é difundido à escala global, desde a OCDE à União Europeia, a revisitaçáo crítica de certos autores clássicos e de alguns trabalhos pioneiros se revela, em meu entender, indispensável. Não se trata, apenas, de acumular a necessária erudição e cultura sólida na nossa área de trabalho, de conhecer os precursores e os seus contextos de produção, de os poder seguir ou criticar, mas também de ganhar amplitude de análise e distância crítica, aprofundando as genealogias dos conceitos e cuidando da sua historicidade, evitando a sua reificação, desnaturalizando a sua adesáo e o seu protagonismo político e mediático, rompendo com o senso comum.

A alternativa é a de alienar a reflexão teórico-conceptual a favor dos slogans da moda, das categorias jurídicas, dos lemas políticos, como se fossem estes a fonte de legitimidade do trabalho académico, o quadro de valores a seguir, a matriz conceptual a adoptar, em vez da condição de objectos privilegiados de uma hermenêutica, do debate teórico e do trabalho empírico. Uma alternativa que se revelaria uma ingenuidade normativista, um erro epistemológico ou, no limite, um enviesamento de tipo ideológico, todos incompatíveis com o trabalho académico e com a autonomia do investigador.

É neste quadro que se justifica plenamente o estudo das fontes primárias e também dos trabalhos de apropriação crítica e de recontextualização elaborados pelos pioneiros, capazes de sustentar uma análise dos ideais de "Educaçáo Permanente" e do conceito de "Educação de Adultos", a título de exemplo, desde a década de 1960 até ao presente, pois o primeiro conceito permanece activo em vários lugares do mundo, e desde logo na vizinha Espanha, e, em seu torno, das distintas tradiçôes politico-educativas, filosóficas e pedagógicas de "Educação de Adultos", bem como o estudo do complexo processo de ressemantização de muitas palavras-chave que continuamos a usar, mas agora sob quadros de inteligibilidade e sob racionais educativos consideravelmente distintos, remetendo já, afinal, para conceitos igualmente diversos.

De entre os nossos autores pioneiros no estudo das matérias de Educação Permanente e de Adultos, ainda na década de 1960, destaca-se o opúsculo de Manuel Breda Simóes (1965), editado pela Fundação Calouste Gulbenkian com o título Pedagogia Concreta, Educação Permanente e Formaçâo Psicossocial; a partir da década de 1970, destaco aqui os trabalhos, de incontornável interesse, de: Pedro Morais Barbosa, com o seu livro, de 1971, intitulado Coordenadas da Educação Permanente, onde assume como lema "educação - sempre, para todos e por tudo"; o texto de João Evangelista Loureiro, publicado em 1975 com o título Introdução à Teoria Geral da Educação de Adultos, editado pela Universidade do Minho; também editados por esta instituição, os trabalhos de conceptualização filosófica e educativa publicados por José Ribeiro Dias, a partir da obra colectiva intitulada Educação de Adultos, com data de 1978, designadamente "Introdução Histórica”, "A Educação de Adultos numa Perspectiva Humana (Personalista Integral)", e ainda "Como Entender Correctamente a 
Educação de Adultos"; nesta mesma obra, também o capítulo de Henrique Barrilaro Ruas, intitulado "Educação de Adultos em Portugal, no Passado e no Presente"; de Alberto Melo e Ana Benavente o importante relatório publicado em 1978 pela UNESCO, intitulado Educação Popular em Portugal (1974-1976) e ainda sobre o mesmo período histórico o artigo de Alberto Melo intitulado "Portugal's Experience of Reform Through Popular Initiative", o primeiro publicado por um português na revista Convergence, do International Council for Adult Education e ainda "Nove Meses na DGEP. Uma Educaçáo Feita por Todos", publicado em 1979 na revista Raiz e Utopia. Finalmente, de António Simóes, o seu artigo, de 1975, um dos primeiros textos sobre Educação Permanente publicados por um autor português no estrangeiro, no caso na La Nouvelle Revue Pédagogique (30, no8, pp. 449-462) e em 1977 o artigo "Educação Permanente e Educação Compensatória", publicado na Revista Portuguesa de Pedagogia (XI, pp. 139-147). Em 1979, ano em que defendeu a sua tese de doutoramento, a primeira em Ciências da Educação atribuída em Portugal, o autor publicou dois importantes trabalhos, emblemáticos quanto ao seu percurso académico posterior: o artigo intitulado "O Adulto em Perspectiva: diferenças de comportamento associadas à idade", na Revista Portuguesa de Pedagogia (XIII, pp. 3-66), e a sua tese de doutoramento, Educação Permanente e Formação de Professores, editada em Coimbra pela Almedina.

Esta última trata-se, sem dúvida, do primeiro trabalho de fôlego académico sobre a temática, com uma rica e actualizada bibliografia, onde se destaca o rigor conceptual e a novidade dos temas abordados, bem como alguns dos autores hoje considerados clássicos no estudo da Educação Permanente e da Educação de Adultos, como P. Bélanger, J. Dumazedier, E. Faure, R. Hutchins, P. Lengrand, ou J. Le Veugle. De entre os autores portugueses, refere trabalhos dos já acima indicados José Ribeiro Dias, Alberto Melo e Henrique Barrilaro Ruas. Ao abordar, neste livro, o carácter ambíguo do conceito de Educação Permanente, António Simóes integra-se já numa perspectiva crítica, que não mais viria a abandonar, como aqui se verá, afastando-se quer de "iluminismos pedagógicos", quer de concepçóes pragmatistas e instrumentais. A esse propósito vale a pena citar a clareza da sua posiçáo, por referência aos avanços da França no domínio da formação profissional, quando afirma: "[...] não parece que, em países, como a França, onde a formação profissional teve institucionalizaçáo legal, se tenha com isso avançado para uma verdadeira Educaçáo Permanente, pois aquela se tem geralmente limitado a satisfazer as exigências de adaptação ao trabalho [...]" (Simóes, 1979b, p. 300), posiçáo congruente com a de outros importantes autores, ainda hoje, designadamente em França, como é o caso de Lucie Tanguy.

Iniciava-se, em Portugal, uma reflexão sistemática, ainda que à nossa escala, em torno da Educação de Adultos, através de duas vias diferenciadas e, em ambos os casos, de forma tentativa e relativamente pouco expressiva. Por um lado, trabalhos de carácter técnico, por exemplo no quadro de estudos elaborados pela Direcção-Geral de Educaçáo de Adultos, designadamente em contexto de preparaçáo do Plano Nacional de Alfabetização e Educação de Base de Adultos (PNAEBA), através da acção de novos autores que iniciaram os seus trabalhos ainda em finais da década de 1970, mas com expressão mais significativa a partir da década seguinte. Por outro lado, a publicação de trabalhos no âmbito de projectos de intervenção socioeducativa e de desenvolvimento local, e um ou outro trabalho relativo a provas académicas, ainda raras. Como haveria de concluir mais tarde António Simôes, em entrevista concedida no âmbito do "estado da arte" da investigação portuguesa em Educação de Adultos, que realizei com Paula Guimarães em 1994, para a Sociedade 
Europeia de Investigação em Educação de Adultos (ESREA), o trabalho de investigação era então realizado de forma marcadamente individual, quase sempre à margem de projectos e de financiamentos institucionais (Simóes, 1994). Surge, em todo o caso, entre as décadas de 1980 e 1990, a produção, relativamente inédita face ao período anterior, de vários autores, de que lembraria, a título exemplificativo, e para além dos já antes referidos Alberto Melo, António Simóes, Ana Benavente, Rogério Fernandes, trabalhos de Lucília Salgado, Rui Canário, José Alberto Correia, António Inácio Nogueira, Amélia Vitória Sancho, Augusto Santos Silva, Maria José Esteves, Fernando Henrique Belchior, Orlando Garcia, Abílio Amiguinho, Artur Cristóvão, José Portela, Almerindo Afonso, Justino Magalhães, Rosa Lima, entre outros. Será, sobretudo, a partir de finais dos anos noventa, que uma nova geraçáo de autores e de estudos emerge de forma mais expressiva, até à actualidade, configurando uma situação que, não sendo porventura exemplar é, porém, a mais pujante alguma vez registada na nossa história pouco significativa de trabalhos no campo. Sem propósitos de inventário exaustivo, que urge elaborar, mas, pelo contrário, de forma meramente indicativa, lembro aqui contribuições, com certa continuidade, de autores como Albertina Oliveira, Ana Luísa Pires, António Firmino da Costa, António Fragoso, Armando Loureiro, Cármen Cavaco, Clara Oliveira, Cristina Vieira, Fátima Antunes, Fátima Barbosa, Fernando Ilídio Ferreira, Joaquim Armando Ferreira, Joaquim Coimbra, Luís Alcoforado, Luís Imaginário, Luís Rothes, Manuela Terraseca, Margarida Pedroso Lima, Maria do Loreto Couceiro, Patrícia Ávila, Paula Guimarães, Rosanna Sá. Estes e outros autores, a partir de inscriçóes disciplinares e de matrizes teóricas diversas, têm enriquecido o campo de estudos no âmbito da Educaçáo e Formação de Adultos, ora mais centrados em focalizaçôes típicas das Ciências das Educação, ora transportando contribuiçôes provindas de outras áreas, como a Sociologia e a Psicologia.

Em geral, permanece um certo domínio das contribuiçôes resultantes de provas académicas, muitas das quais, de resto, orientadas pelos investigadores mais antigos já referidos. É contudo visível, e também plausível, que a partir de agora se faça sentir a influência da acção de um mais numeroso e diversificado número de investigadores, a tal ponto que se pode afirmar que nunca, como hoje, dispusemos de tantos investigadores e de uma produção académica tão pujante.

Também aqui se tem feito sentir a acção, de várias décadas de trabalho e de lançamento metódico e persistente das bases necessárias à consolidação do campo, empreendidas pelo Prof. António Simóes. Lembraria, a propósito, os impactos significativos que resultaram da sua coordenação da Secção de Educação de Adultos da Sociedade Portuguesa de Ciências da Educação, da direcção das várias ediçóes das Jornadas de Educação de Adultos, realizadas aqui na Universidade de Coimbra, da publicação de actas de reuniôes científicas e de números da Revista Portuguesa de Pedagogia, da criação e direcção do Mestrado em Educação, Formação de Adultos e Intervenção Comunitária, da fundação e direcção do Núcleo de Assistência Psicológica e de Formação de Adultos e, ainda, da direcção do Centro de Psicopedagogia da Faculdade de Psicologia e de Ciências da Educação da Universidade de Coimbra. A par do trabalho de investigação em áreas como a educação permanente e a formação de professores, a educação básica de adultos, o desenvolvimento cognitivo do adulto, a memória do adulto, a atitude dos adultos face à morte, a aprendizagem autodirigida, ou o envelhecimento e a educação dos idosos, tema do seu livro mais recente, em que por várias vezes inaugurou no país temas e linhas de pesquisa inovadoras, António Simôes formou uma nova geração de investigadores universitários e com eles tem realizado 
um trabalho em equipa que sobressai no panorama, ainda bastante individualista, da produção académica na nossa área. A colaboração com Albertina Oliveira, António Fonseca, Armanda Matos, Cristina Vieira, Joaquim Armando Ferreira, José Augusto Rebelo, Luís Alcoforado, Margarida Pedroso Lima, Maria das Dores Formosinho ou Maria do Rosário Pinheiro, entre muitos outros, é bem a expressão disso mesmo.

Da mais de uma centena de trabalhos que publicou até agora, no país e no estrangeiro, sobressai ainda a capacidade de articulação, notável, de temas e problemas de investigação altamente especializados, através de métodos quantitativos elaborados e rigorosos, por um lado, e a sua curiosidade e o seu investimento crítico, epistemológico e metodológico, em torno de estilos e métodos de investigação com tradição na pesquisa qualitativa e socio-crítica da Educação de Adultos e da Educação Popular, com destaque para a investigação-acção (Simóes, 1990) e para a investigação participativa (Simóes \& Vieira, 1996). Mesmo quando me fica a ideia de uma certa resistência sua a tais abordagens, firmada numa concepção tão séria e fundamentada quanto ancorada em critérios de apreciação de filiação científica de raiz quantitativa, embora não positivista e, muito menos, objectivista. Esta sua capacidade de problematização epistemológica, em qualquer dos casos, parece-me exemplar e tem motivado incursôes diversas e autónomas por parte de alguns dos seus orientandos, que é o que, exactamente, esperamos de um Mestre.

Quanto à já referida inscrição crítica, ao melhor estilo de uma concepção problematizadora e não axiologicamente neutra de Educação de Adultos, é igualmente apreciável o vigor com que tem confrontado as derivas tecnicistas e pragmatistas da educação e formação, não apenas assumindo e revelando as suas posiçóes, mas também dando testemunho académico do seu saber, solidamente ancorado na história e nas correntes filosóficas e pedagógicas; estas são, cada vez mais, referenciais indispensáveis a quem produz trabalho de investigaçáo nesta área, pelo menos na perspectiva de uma pesquisa $\mathrm{em}$ Educação de Adultos e não, apenas, sobre Educação de Adultos.

São muitas, e já para além das minhas possibilidades numa circunstância como esta, as marcas do que acabo de afirmar, plasmadas em vários trabalhos e, especialmente, em introduçôes a certas publicaçóes e em discursos públicos em congressos e reuniôes científicas. Não posso, contudo, deixar de referir o seu acompanhamento crítico da situação das políticas de Educaçáo de Adultos em Portugal, ou da ausência destas, ou ainda da sua intermitência, dos avanços e recuos, sem rumo certo e minimamente estável, ao longo das últimas décadas.

No discurso de abertura das I Jornadas de Educação de Adultos, realizadas em Abril de 1994, (Simóes, 1996), não hesita em reconhecer que "não sopram ventos favoráveis à educação de adultos", registando o "agudizar do economicismo" e uma concepção política reducionista, face a uma perspectiva da Educação de Adultos como fenómeno global e polifacetado, que inclui "[...] a alfabetização, mas também a formação profissional, e bem assim a educaçáo dos pais, e, do mesmo modo, a gerontologia educativa, e também a educação para a saúde, e ainda a animação socio-cultural e, finalmente, a aprendizagem auto-dirigida, na sua riqueza de formas e multiplicidade de expressóes" (Ibid.: 14). Aqui regista aquilo que designa como "duas maneiras alternativas de encarar a educação de adultos"; por um lado, "atribuindo-lhe um papel passivo, de adaptação às mudanças ocorridas e de conformaçáo com as políticas instituídas" e, por outro, "enfatizando, preferencialmente, o seu carácter activo, de emancipação individual e colectiva" (Ibid.), que é a opção que defende. No discurso de encerramento, interroga-se: "Estamos, mesmo, a ultrapassar a dicotomia educação/formação - de uma escola que não queria sujar as mãos com a formação profissional e de uma 
formação, que desprezava as generalidades da educação - ou o privatismo e o economicismo ameaçam exacerbar a dicotomia? Vislumbro que será este um domínio onde se jogará boa parte do futuro da educação de adultos, em Portugal” (Ibid.: 499).

Volvidos sete anos, no discurso que proferiu na abertura das II Jornadas, em Março de 2001, sobre modelos e práticas de educação de adultos, critica a fragmentação administrativa desta, através da sua divisão por dois distintos departamentos do Ministério da Educação, que ocorrera em 1993, e observa: "[...] culminando um longo processo de degradação e descaracterização, a educação de adultos agonizava. Só a fé mantinha acesa a esperança, que permitia iluminar as trevas do pessimismo reinante" (Simóes, 2001: 7). Ao invés, revelava em 2001 um certo entusiasmo pelas potencialidades abertas com a criação da ANEFA, situação em que, afirma, "A educação de adultos reanima-se e vive", saudando a propósito o assumir de responsabilidades por parte do Estado. Retorna, contudo, as interrogaçóes críticas sobre as articulaçóes anunciadas entre educação e formação, que embora considere de saudar, apresentam contornos problemáticos: "[...] porquê a parceria com o Ministério do Trabalho e da Solidariedade, e não com outro ou com outros, visto que todos [...] são parte interessada no processo? Muitas justificaçóes respeitáveis poderão, sem dúvida, aventar-se, umas mais convincentes do que outras. Mas eu não sei de nenhuma que me possa tranquilizar, plenamente. É que paira sobre a educação de adultos a ameaça de se tornar formaçáo de adultos e de a educação continuada se converter em formação profissional continuada” (Ibid.: 8).

Face aos perigos invocados, diria que de forma sábia e bem informada, mas que a falta de visão de certos poderes instituídos tem teimado em desprezar, conclui: "Só me resta fazer um apelo à vigilância, por parte da sociedade civil, das instituiçóes e dos investigadores empenhados na educação de adultos, no sentido de combaterem e contrariarem a tendência à rendição e às tentaçóes economicistas e à hegemonia redutora da formação profissional" (Ibid.). Como sabemos, a vigilância foi de poucos, e frequentemente desprezada sob epítetos diversos, que me dispenso de recordar, até porque, no essencial, continuam a ser utilizados hoje. Neste texto podemos ainda encontrar reflexôes da maior pertinência teórica, com manifestas implicaçôes práticas, quanto ao uso indiscriminado e dominante da noção de "competência", sobretudo quando de forma estreita e subordinada ao trabalho, à empregabilidade e à adaptabilidade, o que conduz o autor a chamar a atenção para a raiz comum (petere), bélica e competitiva, presente quer em "competitividade" quer em "competência”, argumento que também usei para revelar o carácter pleonástico do lema, então em voga, "competências para competir", um derivado do lema da economia, proposto uns anos antes por Michael Porter para a educação - "competir para progredir", no quadro mais geral daquilo que designo de uma "pedagogia contra o outro".

Finalmente, na nota de abertura ao número temático sobre "Educação e Formação de Adultos", da Revista Portuguesa de Pedagogia (vol. 41, n³, de 2007), lamenta abertamente que as esperanças que depositara na acção da ANEFA não tenham sido cumpridas, mesmo sem desvalorizar a acção empreendida por este instituto público, sobretudo porque a ANEFA "[...] cumpriu melhor o seu programa de formação do que o programa de educação" (Simóes, 2007: 6). Comentando a extinção daquele organismo e a criação da Direcção-Geral de Formação Vocacional, em 2002, conclui: "Embora fosse apresentada como a continuadora das tarefas da ANEFA, a própria designação poucas dúvidas deixava, sobre o seu real alcance - o de reduzir a educação de adultos à qualificação dos recursos humanos" (Ibid.: 7). Em 2006, como se sabe, foi criada, de novo com o estatuto jurídico de instituto público, a ANQ (Agência Nacional para a Qualificação), que segundo o autor, 
"No essencial, não difere da DGFV, no que concerne às suas atribuições, concentrando-se a atençáo do legislador na qualificação dos portugueses, como sugere a própria designação da Agência e a Iniciativa Novas Oportunidades confirma” (Ibid.). Situação hoje institucionalizada, independentemente de alguns dos sucessos e benefícios entretanto atingidos, que ninguém ignora; todavia de forma claramente insular face àquilo que o país exigiria de uma política pública, não reducionista, de Educação de Adultos. Esta, porém, ausente entre nós, mesmo como concepçáo de futuro, no actual discurso oficial, com manifestas resistências em integrar outras valências ou dimensões, e muitas práticas socioeducativas diferenciadas, ainda que não promovidas directamente pelo Estado, como ficou bem expresso no relatório sobre o "estado da arte" que o governo português apresentou em 2009 à VI CONFINTEA, em Belém do Pará. Em profundo contraste, diga-se, com os documentos apresentados por outros governos, mesmo no quadro dos da União Europeia.

Aqui ficam, de forma necessariamente breve e muito lacunar, algumas das relevantes contribuiçôes de António Simóes, fatalmente representadas pelos meus interesses e pelas minhas capacidades e dificuldades de apreensão de uma obra vasta, polifacetada e, em certos casos, já para além do meu saber relativamente a certas áreas da Psicologia da Educação. Mas é isso mesmo que mais aprecio nele, e também essa capacidade de não se deixar aprisionar por temas restritos, por modas passageiras e pelo espírito do tempo, naquilo que este comporta de subordinação progressiva da educação à economia.

Sei, de há muitos anos, como o autor é avesso a certos protagonismos e como a sua sobriedade e rigor académico são incompatíveis com este tipo de manifestaçôes, que justamente aqui nos reúne, neste momento. Mas ele sabe, do mesmo modo, como sou indiferente a discursos de conveniência ou de circunstância. E, por isso, tudo se pode resumir, afinal, a um convite à leitura da obra do autor, independentemente de concordâncias e discordâncias e, sobretudo, para além da busca, mais ou menos cirúrgica e insular, de citaçóes reverenciais, tão em voga.

Quanto ao futuro das suas contribuiçôes para o estudo da Educação de Adultos, ninguém estará hesitante. Estruturalmente, sabemos, até pelos seus trabalhos, que as pessoas mais velhas "conservam a sua capacidade de aprender", por referência a uma nova concepção de educação, entendida como "processo coextensivo à duração da vida", nas suas próprias palavras (Simóes, 1999, p. 8, e também 2006). Ou ainda, como afirmou o filósofo francês Helvetius, em 1773, "O curso da minha vida não é mais do que um longo processo de educação", isto muito antes da descoberta politico-conceptual da educação informal. Por outro lado, sabemos que, no seu caso, uma tão longa dedicação, quase amorosa, como diria o "andarilho da utopia" e referência universal da Educação de Adultos, afortunadamente em língua portuguesa, não vai, seguramente, abrandar. Liberto de constrangimentos institucionais, cada vez maiores e mais burocraticamente absorventes, melhor poderá explorar a sua autodirectividade.

Vamos, pois, continuar a aprender consigo e a apreciar as suas contribuiçóes científicas, pedagógicas e cívicas.

Atravessando quatro décadas, desde meados de 1970, o trabalho do Prof. António Simôes é um testemunho do carácter multiforme e plurifacetado da Educação de Adultos, transcendendo os elementos que, em todas as fases, e também hoje de forma insidiosa, lhe procuraram reduzir drasticamente a amplitude e a natureza crítica.

É também por isso que o Prof. António Simóes deve ser considerado já um autor clássico da Educação Permanente e de Adultos em Portugal. 


\section{Referências Bibliográficas}

Barbosa, Pedro Morais (1971). Coordenadas da Educação Permanente. S. L.: Publicaçôes Europa-América.

Dias, José Ribeiro (1978). "Introdução Histórica”. In M. J. Gusmão \& A. J. Gomes Marques (Orgs.). Educação de Adultos. (pp. 9-57). Braga: Universidade do Minho.

Dias, José Ribeiro (1978). “A Educação de Adultos numa Perspectiva Humana (Personalista Integral)”. In M. J. Gusmão \& A. J. Gomes Marques (Orgs.). Educação de Adultos. (pp. 79-94). Braga: Universidade do Minho.

Dias, José Ribeiro (1978). "Como Entender Correctamente a Educação de Adultos”. In M. J. Gusmão \& A. J. Gomes Marques (Orgs.). Educação de Adultos. (pp. 115-146). Braga: Universidade do Minho.

Helvetius, Claude (1773). De L'Homme, de ses Facultés Intellectuelles et de son Éducation. (1'a edição). Londres: Chez la Société Typographique, 2 vols.

Lima, Licínio C. (2007). Educação ao Longo da Vida. Entre a Mão Direita e a Mão Esquerda de Miró. São Paulo: Cortez.

Loureiro, João Evangelista (1975). Introdução à Teoria Geral da Educação de Adultos. Braga: Universidade do Minho. Melo, Alberto (1978). "Portugal's Experience of Reform Through Popular Initiative”. Convergence (1).

Melo, Alberto (1979). “Nove Meses na DGEP. Uma educação Feita por Todos”. Raiz \& Utopia, no 9/10.

Melo, Alberto \& Benavente, Ana (1978). Educação Popular em Portugal (1974-1976). Lisboa: Livros Horizonte.

Ruas, Henrique Barrilaro (1978). "Educação de Adultos em Portugal, no Passado e no Presente". In M. J. Gusmão \& A. J. Gomes Marques (Orgs.). Educação de Adultos. (pp. 269-300). Braga: Universidade do Minho.

Simões, António (1975). "Quelques Réflexions Concernant les Fondements Philosophiques de l'Éducation Permanente". La Nouvelle Revue Pédagogique, 30 (8), 449-462.

Simóes, António (1977). "Educação Permanente e Educação Compensatória". Revista Portuguesa de Pedagogia, $X I, 139-147$.

Simóes, António (1979a). "O Adulto em Perspectiva: diferenças de comportamento associadas à idade”. Revista Portuguesa de Pedagogia, XIII, 3-66.

Simóes, António (1979b). Educação Permanente e Formação de Professores. Coimbra: Almedina.

Simóes, António (1990). "A Investigação-Acção: natureza e validade”. Revista Portuguesa de Pedagogia, XXIV (3), 39-51.

Simões, António (1994). "Professor António Simões". In Licínio C. Lima \& Paula Oliveira (Eds). "State of the Art" Study of Research on the Education of Adults in the European Countries - Portugal. ESREA Research Project. (pp. 62-75). Braga: Universidade do Minho/ESREA.

Simões, António (1996). "Discurso proferido pelo Presidente da Comissão Científica e da Comissão Organizadora". In António Simóes (Org.). Educação de Adultos em Portugal. Situação e Perspectivas. (pp. 13-16). Coimbra: Comissão Organizadora das Jornadas de Educação de Adultos em Portugal.

Simóes, António (1999). "A Educaçáo dos Idosos: uma tarefa prioritária”. Revista Portuguesa de Educação, 12 (2), 7-27.

Simões, António (2001). "Discurso de Abertura das 2aas Jornadas Modelos e Práticas de Educação de Adultos". Revista Portuguesa de Pedagogia, 35 (1), 7-11.

Simōes, António (2006). A Nova Velhice. Um Novo Público a Educar. Porto: Âmbar.

Simôes, António (2007). "Nota de Abertura”. Revista Portuguesa de Pedagogia, 41 (3), 5-9 (número temático sobre Educação e Formação de Adultos).

Simóes, António \& Vieira, Cristina C. (1996). "A Investigação Participativa: uma investigação com (pelas) pessoas e não sobre (para) as pessoas". Revista Portuguesa de Pedagogia, XXX (3), 57-81.

Simóes, Manuel Breda (1965). Pedagogia Concreta, Educação Permanente e Formação Psicossocial. Lisboa: Fundação Calouste Gulbenkian (Caderno CIP no 1 ).

Tanguy, Lucie (2003). "La Formation Permanente em France, Genèse d'une Catégorie (1945-1971). In AAVV. Cruzamento de Saberes, Aprendizagens Sustentáveis. (pp. 119-128). Lisboa: Fundação Calouste Gulbenkian. 

Série Documentos

Imprensa da Universidade de Coimbra

Coimbra University Press

2011

- U

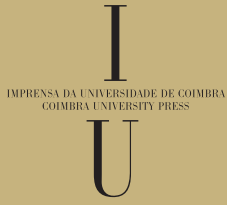

